\title{
Public health ABStractS
}

\section{GUNS AND SUICIDE}

Experience in Canada and the United States indicates that gun control legislation may have led to decreased use of guns by suicidal men, but the difference was apparently offset by an increase in suicides by leaping.

However there does appear to be an advantage from the prevention of suicide point of view, to control availability of guns, particularly to people who have been diagnosed as having mental disorders.

Rich CL, Young JG, Fowler RC, Wagner J and Black NA, Guns and Suicide: Possible Effects of Some Specific Legislation, American Journal of Psychiatry 1990, 147,342 .

\section{GUNS AND VIOLENCE IN AUSTRALIA}

Guns are important because they make violence more violent. Unless one is very expert it takes a while to kill one with one's bare hands - there may be time for a second thought - but with a firearm intention becomes achievement in the blink of an eye. The more guns there are in a community the more shooting occurs, as for example, the homicide rate in the United States which is several times that of comparable but less heavily armed populations.

Common sense suggests a number of measures which might save lives. We should be more concerned about alcohol abuse and there should be more determined follow-up of the domestic arguments which are significantly tumultuous to attract the attention of the neighbours and the police. Since guns kill, we should limit their possession to those who can establish an iron-clad need for them.

Ellard J, Guns and Violence in Australia, Med J Aust $1990,152,394$.

\section{TASMANIAN HEART ATTACKS}

Mortality from coronary heart disease has fallen by about 50 per cent in Australia over the past 20 years and now accounts for about 25 per cent of all deaths.

In Tasmania the rate of decline in mortality is significantly less for all causes and for coronary heart disease. Analysis demonstrates that Tasmanians have not been as prudent in adopting healthy lifestyles as have other Australians. They tend to smoke more and eat more fatty foods, including butter, than other Australians.

Sexton PT, Woodward DR, Gilbert N and Jamrozik K, Interstate Differences in Trends in Coronary Mortality and Risk Factors in Australia, Med J Aust 1990, 152, 531.

\section{EfFECTS OF CHEMICAL WASTE}

Recent years have seen increased concern over possible health effects of exposure to hazardous waste sites on Australian residential communities. Concern has been expressed by residents of Kingston, a town near Brisbane, about chemical wastes in three sites near their community.

Scientific examination of the health consequences has found:

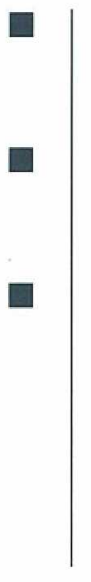

That people living close to the chemical waste site did not report an elevated level of serious physical disease, cancer or death.

People in Kingston reported poorer general health, miscarriages, and considerably higher levels of stress and anxiety.

The reported symptoms of poor physical health above correlate significantly with measures of stress arising as a reaction to the environmental problem and with the belief about direct exposure to the chemicals, but do not appear to be related to the proximity of the site or duration of residence in the area.

This lack of impact of chemical wastes in health, as distinct from environmental, terms is a common international finding.

Dunne MP, Burnett P, Lawton J and Raphael B, The Health Effects of Chemical Waste in an Urban Community, Med J Aust 1990, 152, 592.

\section{EARLY TREATMENT FOR HIV}

Millions of people are infected with HIV worldwide. In about half, the acquired immunodeficiency syndrome (AIDS) develops within a 10-year period. Thus the full force of the epidemic has not yet been felt.

In 1986 zidovudine (formerly AZT) was shown to decrease the frequency and severity of infections and the mortality rate in patients who had already been given the diagnosis of advanced HIV disease. For patients in the late stages of the disease, the hope of prolonged life has become a reality.

The next crucial question is whether it will be beneficial in the earlier stages in slowing the progression of HIV infection and prolonging health. Large-scale testing of this strategy has been undertaken in two major American trials, whose results are now available. They show there is a strong suppression of the effect of HIV infection at relatively low doses of zidovudine therapy.

This finding represents a major and extremely timely advance in the treatment of HIV infection and has profound implications for patients, physicians and health policy. In particular, the results should encourage people who may be at risk for HIV infection to be tested for the virus.

Friedland GH, Early Treatment For HIV, $N$ Eng J Med $1990,322,14,1000$. 